\title{
Autistic-Like Syndrome in Mu Opioid Receptor Null Mice is Relieved by Facilitated mGluR4 Activity
}

\author{
Jérôme AJ Becker ${ }^{1,5}$, Daniel Clesse ${ }^{2}$, Coralie Spiegelhalter ${ }^{3}$, Yannick Schwab ${ }^{3,6}$, Julie Le Merrer ${ }^{1,4,5}$ and \\ Brigitte L Kieffer*, I, , ,
}

'Département de Médecine Translationelle et Neurogénétique, Institut de Génétique et de Biologie Moléculaire et Cellulaire, INSERM U-964, CNRS UMR-7 104, Université de Strasbourg, IIIkirch, France; ${ }^{2}$ Département de Neurobiologie des rythmes, Institut des Neurosciences Cellulaires et Intégratives, CNRS UPR-3212, Strasbourg, France; ${ }^{3}$ Imaging Center, Institut de Génétique et de Biologie Moléculaire et Cellulaire, INSERM U-964, CNRS UMR-7104, Université de Strasbourg, IIIkirch, France

\begin{abstract}
The etiology of Autism Spectrum Disorders (ASDs) remains largely unknown. Identifying vulnerability genes for autism represents a major challenge in the field and allows the development of animal models for translational research. Mice lacking the mu opioid receptor gene $\left(O p r m l^{-1-}\right)$ were recently proposed as a monogenic mouse model of autism, based on severe deficits in social behavior and communication skills. We confirm this hypothesis by showing that adult Oprm $1^{-1-}$ animals recapitulate core and multiple comorbid behavioral symptoms of autism and also display anatomical, neurochemical, and genetic landmarks of the disease. Chronic facilitation of mGluR4 signaling, which we identified as a novel pharmacological target in ASDs in these mice, was more efficient in alleviating behavioral deficits than the reference molecule risperidone. Altogether, our data provide first evidence that disrupted mu opioid receptor signaling is sufficient to trigger a comprehensive autistic syndrome, maybe through blunted social reward processes, and this mouse model opens promising avenues for therapeutic innovation.

Neuropsychopharmacology (20I4) 39, 2049-2060; do: I 0.1038/npp.2014.59; published online 9 April 2014
\end{abstract}

\section{INTRODUCTION}

Autism Spectrum Disorders (ASDs) are complex neurodevelopmental diseases with high heterogeneity and heritability, whose diagnosis is based on two types of behavioral symptoms: impaired social reciprocity and communication, and restricted range of behaviors, interests, and activities (DSM-5). Secondary-comorbid-symptoms vary substantially and include anxiety disorders, cognitive and motor deficits, aggressive behavior, and epileptic episodes (Johnson and Myers, 2007; Mazurek et al, 2013; Pouw et al, 2013; Robinson, 2012; Veenstra-VanderWeele and Blakely, 2012; White et al, 2012; Whyatt and Craig, 2013). Heterogeneity in ASDs points toward multiple primary causes, with genetic factors playing a critical role. Large-

\footnotetext{
* Correspondence: Professor BL Kieffer, Département de Neurobiologie et Génétique, Institut de Biologie Moléculaire et Cellulaire, I rue Laurent Fries, IIIkirch Cedex 67 404, France, Tel: + 33 (0)3 88 6556 93, Fax: + 33 (0)3 886556 04, E-mail: briki@igbmc.fr

${ }^{4}$ These authors contributed equally to this work.

${ }^{5}$ Current address: Physiologie de la Reproduction et Comportements, CNRS UMR-7247, Nouzilly, France.

${ }^{6}$ Current address: Electron Microscopy Core Facility, European Molecular Biology Laboratory, Heidelberg, Germany.

${ }^{7}$ Current address: Douglas Hospital Research Center, Department of Psychiatry, Faculty of Medicine, McGill University, Montreal (Quebec), Canada.

Received 8 October 2013; revised 28 February 2014; accepted 28 February 2014; accepted article preview online 12 March 2014
}

scale genetic studies in patients and preclinical work using animal models have identified over 280 candidate vulnerability genes for ASD (SFARIgene ${ }^{2.0}$ database, https:// gene.sfari.org/autdb/Welcome.do) (Buxbaum et al, 2012; Delorme et al, 2013; Ecker et al, 2012a; State and Levitt, 2011) and suggest that altered synaptic function and disrupted excitation-inhibition balance contribute to the pathology. Neuroimaging studies have confirmed atypical brain connectivity in ASD patients (Ecker et al, 2012b; Just et al, 2012). The precise cause of these troubles, however, remains largely unknown.

Given the high homology between mouse and human genomes and feasibility of genetic modifications in mice, interest in developing genetic mouse models of ASDs has raised recently, together with the development of dedicated behavioral assessment (Buxbaum et al, 2012; Crawley, 2007; Robertson and Feng, 2011). These models ought to demonstrate face (similarity with clinical symptoms), construct (similarity in causal mechanisms), and predictive (similarity in response to therapeutics) validity; none of the currently available ASD models, however, fully matches such criteria. Nevertheless, they have contributed to a better understanding of the neurobiological substrates of autism and to the identification of novel promising therapeutic trails.

Recently, mice lacking the mu opioid receptor gene $\left(\mathrm{Oprm}^{-1-}\right)$ were proposed as a monogenic model of autism (Oddi et al, 2013). These animals indeed demonstrate major deficits in social behavior: reduced maternal attachment in mouse pups (Moles et al, 2004), altered social 
reward in juvenile mice (Cinque et al, 2012), and blunted response to female vocalizations in adult males (Wohr et al, 2011). Thus animal research highlights the critical role of $\mathrm{mu}$ opioid receptors in social responses, and pharmacological effects of mu opioid drugs in social play and adult attachment have been shown in rodents (Burkett et al, 2011; Trezza et al, 2011). In humans, neural sensitivity to social rejection (Way et al, 2009) and social hedonic capacity (Troisi et al, 2011) show significant association with a common variant $(\mathrm{A} 118 \mathrm{G})$ of the mu opioid receptor gene (Oprm1), suggesting a role of this receptor in modulating social reward. Consistent with this, social acceptance activates mu opioid receptors in the ventral striatum, activation of which predicts the desire for social interaction (Hsu et al, 2013). Finally, genetic studies have detected discrete invalidating mutations of the Oprm1 gene in some ASD patients (SFARIgene ${ }^{2.0}$ database), suggesting that such invalidation may contribute to the development of an autistic syndrome, and providing construct validity for the Oprm1 $1^{-1-}$ mouse model. Whether the absence of mu opioid receptor signaling could lead to a comprehensive autistic-like phenotype in the adult animal, however, has not been tested yet. Here we assessed behavioral, neurochemical, anatomical, and genetic features of ASDs in these animals and, based on gene expression analysis, identified an entirely novel pharmacological target for therapeutic intervention in this pathology.

\section{MATERIALS AND METHODS}

\section{Subjects}

Male and female Oprm1 $1^{+1+}$ and Oprm1 $1^{-1-}$ mice (Matthes et al, 1996) aged 6-8 weeks were bred in-house on an identical hybrid background: 50\% 129SVPas-50\% C57BL/ $6 \mathrm{~J}$. For the purpose of the present study, Oprm1 $1^{+/+}$and Oprm $1^{-1-}$ pups were nurtured by Oprm1 $1^{+/+}$and Oprm $1^{-1-}$ parents, respectively, except for cross-fostering experiment. Except otherwise stated, animals were group housed and maintained on a 12-h light/dark cycle (lights on at 070 hours) at controlled temperature $\left(21 \pm 1^{\circ} \mathrm{C}\right)$; food and water were available ad libitum. Experiments were analyzed blind to genotypes. Experimental procedures were reviewed and approved by the Comité Régional d'Ethique en Matière d'Expérimentation Animale de Strasbourg (CREMEAS, 2003-10-08-[1]-58).

\section{Behavioral Experiments}

Detailed behavioral protocols are described in Supplementary Materials and Methods. Social abilities were explored using the direct social interaction, the three-chamber, and the nest-building tests; aggressiveness was evaluated using the resident-intruder test. Stereotyped behavior was assessed by scoring motor stereotypies and measuring spontaneous alternation in a Y-maze. Anxiety-like behavior was evaluated in the marble burying and noveltysuppressed feeding (NSF) tests. Motor function was assessed using the string and grip tests, skill motor learning task, and footprint analysis. Sensitivity to seizures was assessed by scoring penthylene tetrazole-induced convulsions. Experiments were performed on separate cohorts of naive animals (Figures 1 and 2), except for tests exploring motor function (string test, grip test, accelerating rotarod, footprint analysis, in this order), cross-fostering experiment (Supplementary Figure S3), and pharmacological experiments (Figures 4 and 5), where behavioral testing was performed in a battery (time lines in Supplementary Figures S3a and S5a,g). Equivalent numbers of male and female animals were used in each experiment, except for the resident/intruder test, performed only in males.

\section{Real-Time Quantitative PCR Analysis}

Brains were removed and placed into a brain matrix (ASI Instruments, Warren, MI, USA). Prefrontal cortex (PFC), caudate putamen $(\mathrm{CPu})$, nucleus accumbens $(\mathrm{Nac})$, central amygdala (CeA) and ventral tegmental area (VTA) were punched out, and medial amygdala (MeA) was dissected, out from 1-mm thick slices. Tissues were immediately frozen on dry ice and kept at $-80^{\circ} \mathrm{C}$ until use. When assessing transcript levels of a collection of genes of interest, we pooled tissue from one male and one female mouse ( $n=5$ samples/genotype) for each brain structure and each genotype, as no significant effect of gender was detected on mutant phenotype. When assessing transcription of immediate early genes $C$-fos and Egrl after social interaction, we processed each sample individually to parallel individual behavioral data ( $n=7-8$ samples/genotype and treatment). RNA was extracted and purified using the MIRNeasy minikit (Qiagen, Courtaboeuf, France). cDNA was synthetized using the first-strand Superscript II kit (Invitrogen, Life Technologies, Saint Thomas, France). qRT-PCR was performed as previously described (Le Merrer et al, 2013). Primer sequences are displayed in Supplementary Table S1.

\section{Drugs}

Pentylenetetrazole (PTZ, Sigma-Aldrich, Saint-Quentin, France) was administered once a week at escalating doses (vehicle, 25, 37.5, $50 \mathrm{mg} / \mathrm{kg}$ i.p.). Scoring was performed immediately after treatment. Risperidone (Sigma-Aldrich) at $0.2 \mathrm{mg} / \mathrm{kg}$ i.p. (Penagarikano et al, 2011) was administered $60 \mathrm{~min}$ before testing. VU0155041 (Tocris, Bristol, UK) at $5 \mathrm{mg} / \mathrm{kg}$ i.p. (Duvoisin et al, 2011) was injected $120 \mathrm{~min}$ before testing. When risperidone and VU0155041 effects were compared with the same vehicle-treated group, control animals were tested $60 \mathrm{~min}$ after vehicle injection. All compounds were administered in a volume of $10 \mathrm{ml} / \mathrm{kg}$; vehicle was $\mathrm{NaCl} 0.9 \%$.

\section{Statistical Analyses}

Statistical analyses were performed using the Statistica 9.0 software (StatSoft, Maisons-Alfort, France). For all comparisons, values of $p<0.05$ were considered as significant. Statistical significance in behavioral, immunohistochemical, electron microscopy, and monoamine concentration experiments was assessed using two to four-way analysis of variance (genotype, treatment, trial, and session effects) followed by Newman-Keuls post-hoc test, except for nesting and convulsion scores, for which significance was tested using the non-parametric Kruskal-Wallis' analysis of variance. A standard principal component analysis (PCA) (Le Merrer et al, 2012) was performed on behavioral and 
a Oprm1 1/*

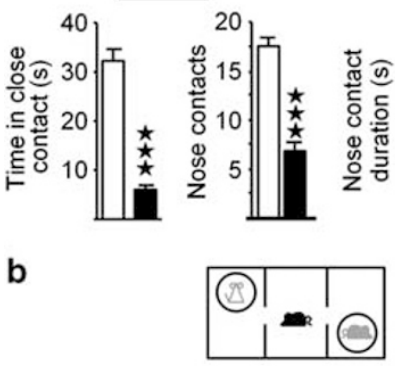
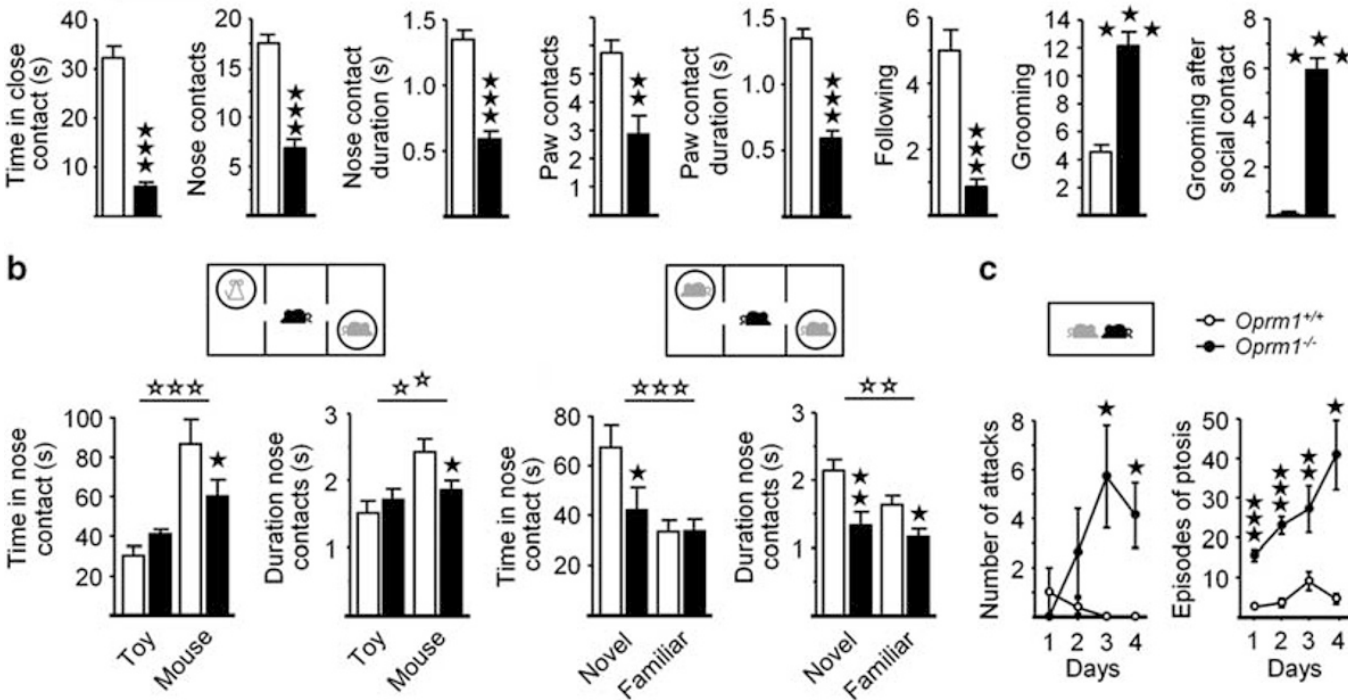

d

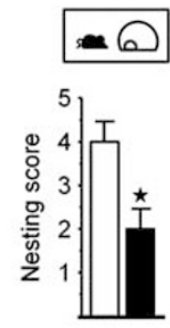

e

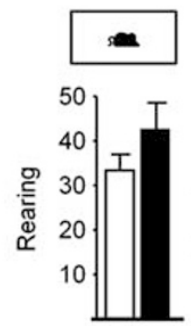

C

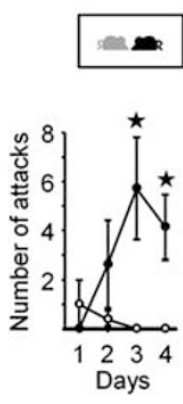

- Oprm1 $1+1$

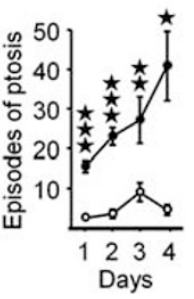

f

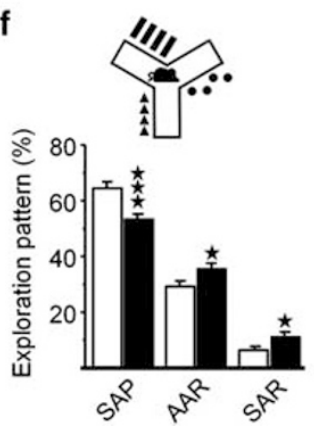

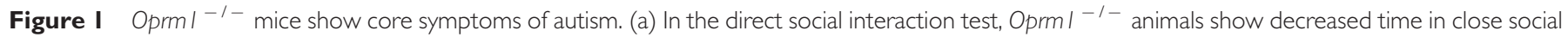

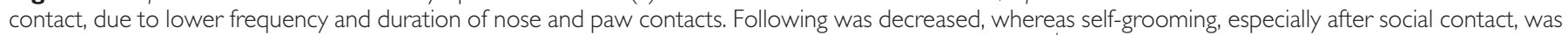

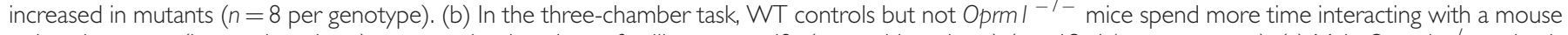

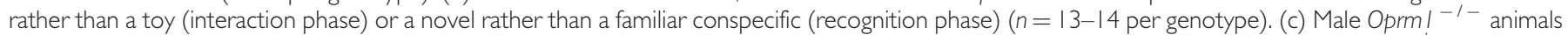

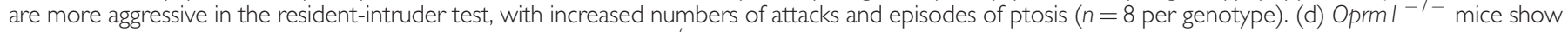

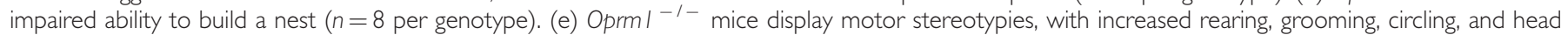

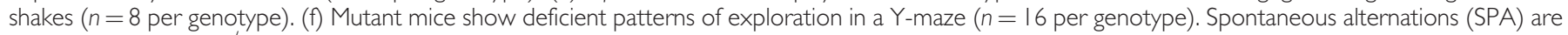

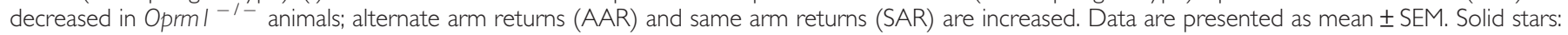
genotype effect, open stars: stimulus effect. One star $p<0.05$, two stars $p<0.0$ I, three stars $p<0.00$ I. See also Supplementary Figure SI.

Fos count data. Loadings for each extracted principal component (PC) are quoted in Supplementary Table S2. We considered the two first extracted PCs (PC1 and PC2) for schematic representation. Significance of qRT-PCR results was assessed after transformation using a one-sample $t$-test, as previously described. Unsupervised clustering analysis was performed on the median of transformed qPCR data using complete linkage with correlation distance (Pearson correlation) for genes and brain region (Cluster 3.0 and Treeview software).

Detailed protocols for Fos immunohistochemistry, electron microscopy, and biogenic amines dosage are described in Supplementary Materials and Methods.

\section{RESULTS}

Oprm1 $^{-/-}$Mice Recapitulate Core Symptoms of Autism

Deficient social interactions are the most remarkable core symptom of autism in humans. We assessed social abilities in Oprm $1^{-1-}$ mice using four tests. In the direct social interaction test, Oprm1 $1^{-9}$ mice spent less time in close interaction with a naive wild-type (WT) conspecific compared with $O p r m 1^{+/+}$controls, due to lower frequency and shorter duration of nose and paw contacts. Similarly, the frequency of followings was reduced in mutants. In contrast, these mice self-groomed more often, particularly after social contact, and for longer than controls, without other detectable motor stereotypies (Figure $1 \mathrm{a}$ and Supplementary Figure S1a, statistics in Supplementary Table S3). In the three-chamber test, Oprm1 ${ }^{+7+}$ but not Oprm1 $1^{-/}$animals spent more time in nose contact with a conspecific $v s$ a toy mouse during the interaction phase. When the toy mouse was replaced by a novel conspecific (recognition phase), Oprm1 ${ }^{+/+}$but not Oprm1 $1^{-/-}$mice spent more time interacting with this unfamiliar animal (Figure 1b and Supplementary Figure S1b, Supplementary Table S3). Defective recognition of a novel social partner did not result from general alteration of recognition abilities, as object recognition was preserved in mutant 
a

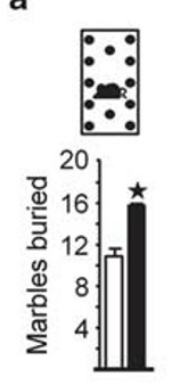

b

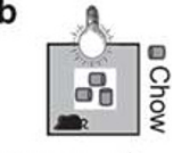

C d

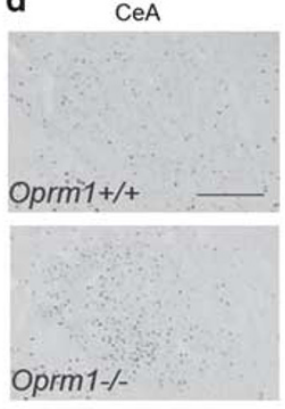

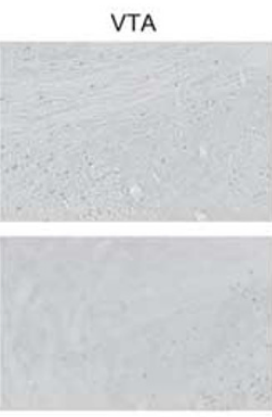

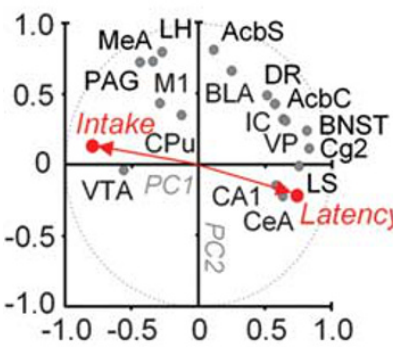

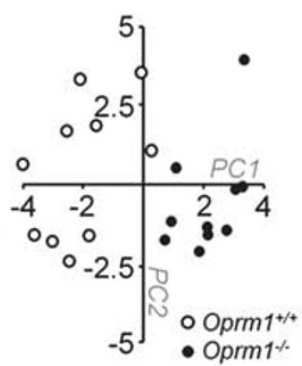

f

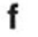

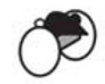

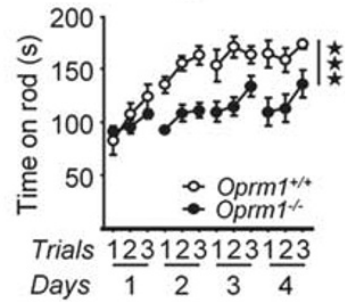

g

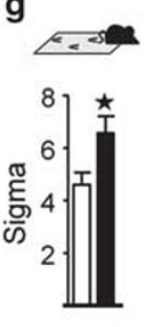

h

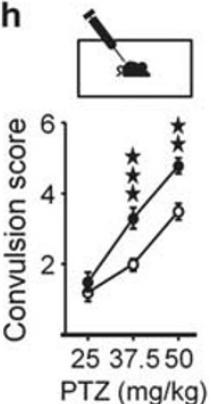

Figure 2 Oprm/ ${ }^{-1-}$ mice display multiple secondary symptoms of autism. (a) Defensive anxiety is higher in mutant animals, hiding more marbles than controls in the marble-burying test ( $n=10$ per genotype). (b) Conflict anxiety is also increased, as shown by longer feeding latencies in the noveltysuppressed feeding (NSF) test ( $n=10$ per genotype). (c, d) Increased anxiety of Oprm $1^{-1}$ mice in NSF is associated with increased number of Fos positive (Fos +) nuclei in the central nucleus of the amygdala (CeA) and decreased Fos staining in the ventral tegmental area (VTA). (e) Principal component analysis on NSF data, including behavioral (red dots) and Fos (grey dots) responses, opposes food intake with latency to eat along the first principal component ( $\mathrm{PCI}, 31.7 \%$ of variance). Fos expression in brain regions implicated in the regulation of anxiety-like behavior clusters with the latency parameter, and Fosstaining in neural circuits involved in the control of reward processes correlates with food intake (left panel: variables' space). Oprm ${ }^{+1+}$ and Oprm I ${ }^{-1-}$ individual mice are dissociated in the subjects' space (right panel). (f, g) Motor function is altered in mutant animals. Oprm ${ }^{-1-}$ mice show impaired motor performance in the accelerating rotarod task ( $n=7$ per genotype) and higher variability of pace size (sigma) in the footprint test ( $n=15-16$ per genotype). (h) Sensitivity to pentylenetetrazole-induced seizures ( $n=8$ per genotype) is increased in mice lacking the mu opioid receptor. Data are presented as mean \pm SEM. Genotype effect: one star $p<0.05$, two stars $p<0.0$ I, three stars $p<0.00$ I. See Supplementary Figure S2 for more tests and parameters and complete list of abbreviations.

animals (Supplementary Figure S1c), or from deficient olfactory perception, as shown in previous studies (Cinque et al, 2012; Moles et al, 2004). We observed that male Oprm $1^{-1-}$ mice displayed signs of aggressiveness in the three-chamber test. We thus assessed the presence of aggressive behavior in these animals using the residentintruder test. Animals were isolated 4 weeks before a naive male was introduced in their home cage, daily for 4 days. In contrast with $\mathrm{Oprm} 1^{+/+}$controls, mutant animals engaged in an increasing number of attacks towards the intruder mouse over sessions with shortening attack latency, together with increasing occurrence of ptosis episodes, a sign of aggressiveness in male mice (Defensor et al, 2012) (Figure 1c, Supplementary Figure S1d, and Supplementary Table S3). Moreover, mutant mice took significantly longer to leave their nest than controls during the first 3 sessions, indicative of exacerbated defensive aggressiveness (Rawleigh and Kemble, 1992) (Supplementary Figure S1d). Thus aggressive behavior, a symptom often associated with ASDs, is increased in Oprm1 $1^{-7-}$ animals. Finally, these mice revealed impaired ability to build a nest in the nesting behavior test (Figure 1d, Supplementary Table S3). Together, these results indicate that adult $\mathrm{Oprm}^{-1-}$ mice display abnormal social abilities, prolonging a recent report of social behavior deficits in juvenile animals (Cinque et al, 2012).
Perseverative, stereotyped behaviors represent another major feature of ASDs, which we tested in mutant mice. When isolated in a novel standard cage, Oprm1 ${ }^{-1-}$ mice displayed more frequent grooming, circling, and head shakes but not rearing or burying than Oprm $1^{+/+}$animals (Figure 1e and Supplementary Figure S1e), suggestive of stereotyped behaviors. We also assessed flexibility and perseveration by performing a continuous spontaneous alternation task in a Y-maze. Mutant animals showed decreased alternation, with increased frequency of alternate and same arm returns (Figure 1e). Increased stereotypic movements and reduced behavioral flexibility in $\mathrm{Oprm} 1^{-/-}$ mice therefore completed autistic-like core symptoms in mutant mice.

\section{Oprm1 $1^{-/-}$Mice Display Multiple Comorbid Symptoms of Autism}

The autistic syndrome also includes several comorbid symptoms with variable expression (reviewed in VeenstraVanderWeele and Blakely, 2012). We first evaluated anxiety levels, as anxiety disorders are commonly associated with ASD. Previous studies have evidenced lower anxiety levels in mutant animals in the elevated plus-maze test (Filliol et al, 2000; Ide et al, 2010). In the present work, we assessed anxiety-like behavior in additional paradigms, the marble 
burying test and the NSF test, which tackle different aspects of anxiety. In the former, mutant animals buried more marbles than controls (Genotype: $\mathrm{F}_{1,16}=6.5, p<0.05$; Gender: $F_{1,16}<1, N S$ ) (Figure 2a), demonstrating increased anxiety-induced stereotypies (Albelda and Joel, 2012). In the NSF, a conflict test challenging approach/avoidance behavior (Aupperle and Paulus, 2010), Oprm $1^{-1-}$ mice took longer to start feeding in the arena center (Genotype: $\mathrm{F}_{1,16}=49.9, p<0.001$; Gender: $\mathrm{F}_{1,16}<1$, NS) and ate less chow when returned to their home cage (Genotype: $\mathrm{F}_{1,16}=20.9, p<0.001$; Gender: $\mathrm{F}_{1,16}<1$, NS) compared with controls (Figure $2 \mathrm{~b}$ ). Oprm1 $1^{-/-}$mice thus show increased conflict anxiety, which involves widespread neuronal activation (Aupperle and Paulus, 2010). We measured such activation using Fos expression as a marker. When compared with Oprm1 $1^{++}$, Oprm1 $1^{-I^{-}}$mice displayed higher Fos expression in brain regions involved in the control of anxiety: CeA, CA1, LS, BNST, Cg2, and DR. In contrast, Fos labeling was lower in regions that modulate reward and motivation processes: VTA and LH (Figure 2c and d; Supplementary Table S4). To correlate behavioral and Fos responses, we performed a PCA on NSF data (Figure 2e, left panel: variables' space, right panel: subjects' space). Interestingly, Fos expression in CeA correlated tightly with the latency to eat, an anxiety parameter, whereas Fos expression in VTA clustered with food intake, a motivation parameter, opposed along a first principal component (PC1, Supplementary Table S2). Remarkably, projection in the subjects' space (Figure 2e right) clearly dissociated Oprm1 ${ }^{+/+}$from Oprm1 ${ }^{-1-}$ individual mice, demonstrating distinct patterns of behavioral responses and neuronal activation across the two mouse populations (Supplementary Table S2). Together, the data indicate that under defensive (marble burying) or conflict (NSF) conditions, mice lacking mu opioid receptors display exacerbated anxiety coherent with the autistic phenotype.

Besides anxiety, we used several tests to assess motor performance and coordination of Oprm1 $1^{-1-}$ mice, as these are often altered in autistic children (Green et al, 2009; Johnson and Myers, 2007). Mice were trained to run on an accelerating rotarod for three trials a day during 4 consecutive days. Oprm1 $1^{-/-}$mice stayed significantly shorter than control animals on the rod over sessions (Genotype: $F_{1,10}=42.5, p<0.001 ;$ Gender: $F_{1,10}<1$, NS; Session: $\mathrm{F}_{3,30}=6.8, p<0.01$; Trial: $\mathrm{F}_{2,20}=25.0, p<0.001$; Genotype $\times$ Session: $F_{3,30}=5.2, p<0.01$; Genotype $\times$ Trial: $\mathrm{F}_{2,20}=5.2, p<0.05$ ) (Figure 2f). Similarly, in the string test, these animals needed more time to grasp the string with a third paw (Genotype: $\mathrm{F}_{1,26}=6.7, \quad p<0.05 ; \quad$ Gender: $\left.\mathrm{F}_{1,26}=1.5, \mathrm{NS}\right)$, although their forelimb muscular strength was unchanged in the grip test (Supplementary Figure S2b and c). Footprint analysis revealed an increased variability of pace length (sigma) in Oprm1 $1^{-1-}$ mice (Genotype: $\mathrm{F}_{1,27}=6.0, p<0.01$; Gender: $\mathrm{F}_{1,27}<1$, NS) (Figure $2 \mathrm{~g}$ and Supplementary Figure S2d). These data demonstrate impaired motor coordination in mutant animals.

Finally, numerous autistic patients suffer from increased susceptibility to seizures (Robinson, 2012). In agreement with earlier studies showing lowered seizure thresholds in response to several convulsant drugs in $\mathrm{Oprm}^{-1-}$ mice (Grecksch et al, 2004; Jang et al, 2001), we found that pentylenetetrazole $(37.5$ and $50 \mathrm{mg} / \mathrm{kg}$ ) induced more severe convulsions in mutants as compared with $O p r m 1^{+/+}$ animals (37.5 mg: $\mathrm{H}_{1,20}=11.6, p<0.001 ; 50 \mathrm{mg}: \mathrm{H}_{1,20}=$ $10.0, p<0.01$; no gender effect) (Figure $2 \mathrm{~h}$ and Supplementary Figure S2e).

\section{Behavioral Deficits in Oprm1 ${ }^{-/-}$Mice Result from the Null Mutation Rather than Parental Care}

We assessed the impact of parental rearing on observed behavioral deficits by performing time-mated cross-fostering of Oprm1 $1^{-1-}$ mice and Oprm1 ${ }^{+/+}$controls (Peca et al, 2011). Cross-fostered mutant animals showed impaired direct social interaction, stereotypic behavior, and anxiety, but not nesting abilities, similar to those observed in Oprm1 $1^{-/-}$mice nurtured by mutant parents (Supplementary Figure S3). These behaviors were not affected in Oprm $1^{+/+}$mice bred by mutant parents.

\section{Oprm1 ${ }^{-/-}$Mice Show Modified Transcription of Several Candidate Genes for Autism}

Multiple genes have been associated to the etiopathology of autism (Ecker et al, 2012a; Insel 2010; State and Levitt, 2011). We quantified transcription levels of a selection of these genes in Oprm1 $1^{+/+}$and Oprm1 $1^{-1-}$ animals across four brain regions critical for emotional/cognitive processes and motor control: the $\mathrm{PFC}, \mathrm{CPu}, \mathrm{NAc}$, and $\mathrm{CeA}$, using a qRT-PCR approach (Figure 3a; Supplementary Figure S4a, Supplementary Table S5). We detected changes in the expression of genes coding for the adhesion and scaffold proteins neuroligins (Nlgn1 and Nlgn2) and SHANK3 (Shank3). Transcriptional levels were also modified for the genes coding transporters of norepinephrine (NE, Slc6a2), dopamine (DA, slc6a3), and serotonin (5HT, slc6a4), as well as several receptors, including beta3 subunit of GABAA receptors (Gababrb3) and 5HT2a serotonin and D2 dopamine receptors. The most dramatic changes in expression were observed for the genes coding the neuropeptides $\mathrm{CRH}$ and oxytocin. Finally, dysfunction of metabotropic glutamate receptors mGluR5 has received major attention as putative causative mechanism in fragile $\mathrm{X}$ syndrome and ASD (Carlson, 2012). Expression of Grm5, coding these receptors, was not modified in Oprm $1^{-1-}$ mice; however, expression of Homer3, coding a key molecular interactor of mGluR5 receptors, was significantly downregulated. Transcriptional modifications observed in mutants were region-specific, prominent in the $\mathrm{CPu}$ and NAc. Inactivation of the mu opioid receptor gene, therefore, alters expression of several candidate genes for ASD, mainly in striatal regions.

\section{Mutant Mice Display Abnormal Striatal Synapses and Modified Transcription of GABA and Glutamate Signaling Genes}

Abnormal basal ganglia function has been proposed as a key feature of autism (Di Martino et al, 2011; Kohls et al, 2012). In this study, deficient social behavior and motor clumsiness associated with stereotypic behavior in Oprm $1^{-/-}$animals point towards ventral and dorsal striatal dysfunction. We used electron microscopy to assess striatal synaptic morphology and observed an increased 


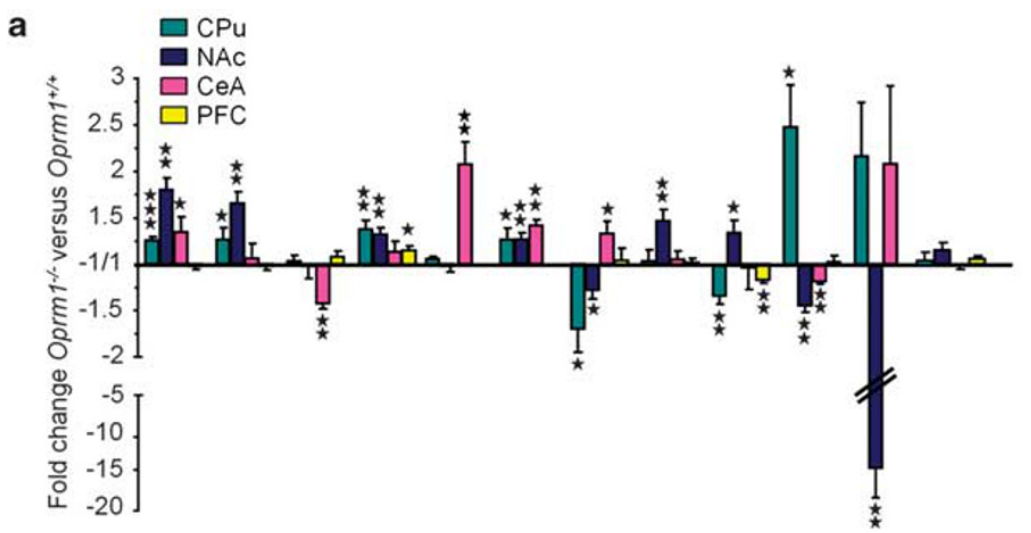

b $\square O p r m 1^{+/ *}=0 p r m 1^{1-}$
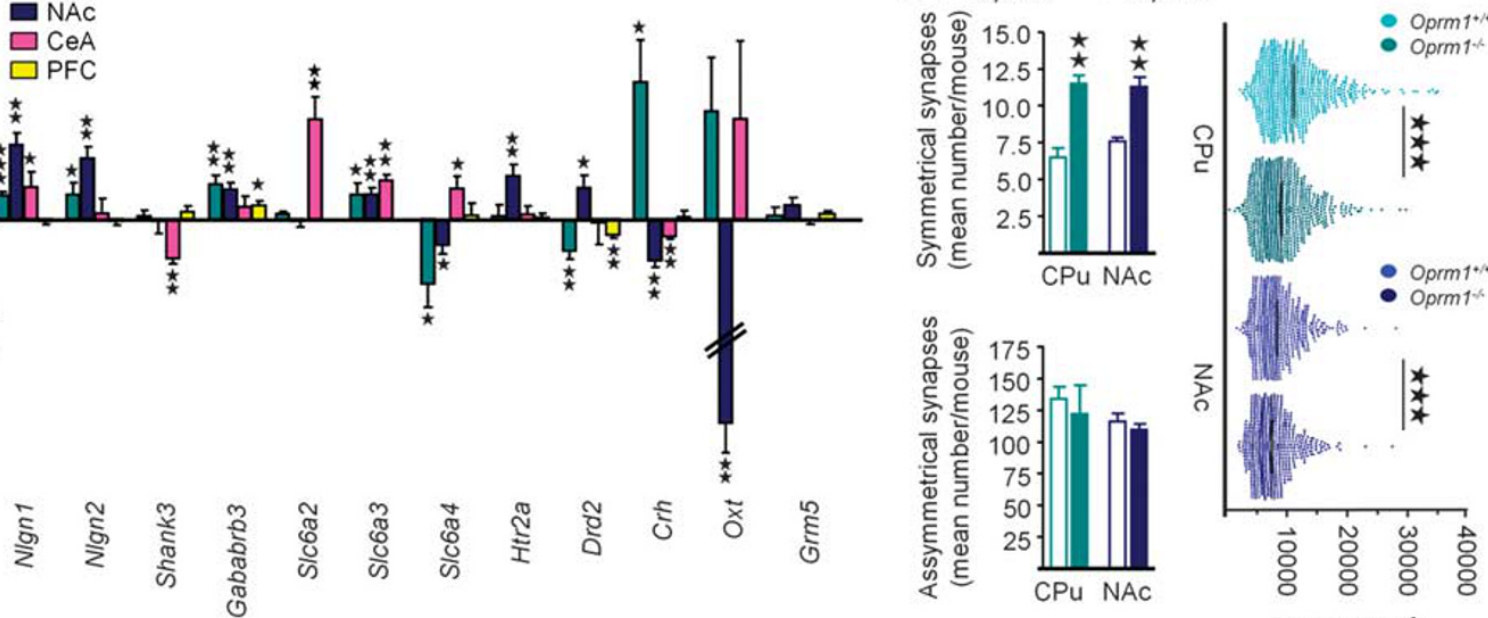

Surface $\left(n m^{2}\right)$
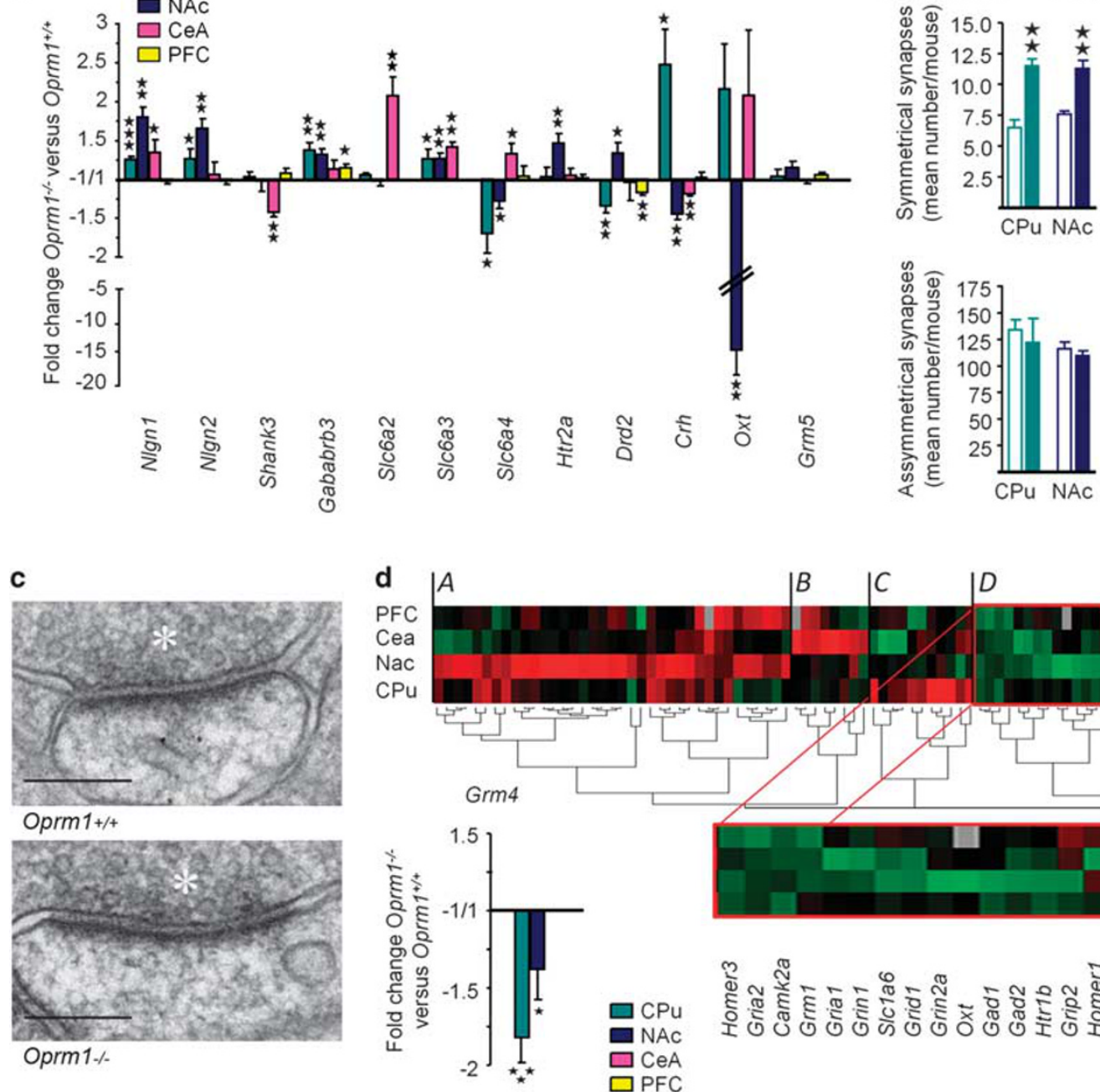

Figure $3 \mathrm{Oprm} \mathrm{I}^{-1-}$ mice display transcriptional modifications and abnormal striatal synapses. (a) Transcription of multiple candidate genes for autism is modified in mutant animals across four brain regions (see details in Supplementary Table S3). (b) Oprm $1^{-1-}$ mice display abnormalities in the number of striatal symmetrical synapses (left panels, 120 frames per mouse at $\times 40000$ magnification). Striatal asymmetrical synapses show reduced surface of postsynaptic densities (right panel). (c) Representative microphotographs $(\times 40000)$ illustrate morphology of striatal asymmetrical synapses in Oprm I $+1+$ and Oprm $/^{-1-}$ mice. Scale bar: $200 \mathrm{~nm}$. Asterisk: presynaptic element. (d) Clustering analysis of gene expression data classifies genes in four clusters (A-D). Cluster (D) gathers genes mostly involved in glutamatergic signaling that all show lowered mRNA levels in the caudate putamen and nucleus accumbens of Oprm I ${ }^{-1}$ mice, among which Grm4 (framed), coding mGluR4 glutamate receptors, was detected only in these regions. Data in (a) and (b) are presented as mean \pm SEM. Genotype effect: one star $p<0.05$, two stars $p<0.0$ I, three stars $p<0.00$ I. CeA, central nucleus of the amygdala; $C P u$, caudate putamen; NAc, nucleus accumbens; PFC, prefrontal cortex. See also Supplementary Figure S4.

number of symmetrical synapses in both $\mathrm{CPu}$ and NAc of Oprm $1^{-1-}$ mice (Genotype: $\mathrm{F}_{1,20}=67.6, p<0.001$; Structure: $F_{1,20}<1, N S$ ), suggesting that inhibitory (GABAergic/ glycinergic) local micro-circuitry is denser in these animals. The number of asymmetrical (glutamatergic) synapses was similar in mutants and controls; however, morphological analysis showed significant reduction in the area $(\mathrm{CPu}$ : $\left.\mathrm{F}_{1,1505}=81.3, p<0.001 ; \mathrm{NAc:} \mathrm{F}_{1,1209}=19.1, p<0.001\right)$, but not length, of postsynaptic densities (PSDs; Figure $3 \mathrm{~b}$ and $\mathrm{c}$ and Supplementary Figure S4b and c). These data strongly suggest that lack of mu opioid receptors alters the normal development of striatal synapses.

Recent studies have revealed abnormal GABA and glutamate metabolism in individuals with autism, notably in striatal regions for the latter (Horder et al, 2013; Rojas et al, 2013). To test for altered signaling within these two major neurotransmitter systems, we performed comprehensive expression analysis of critical GABA and glutamate gene players across previous four brain regions (Supplementary Table S5). We then identified groups of genes sharing similar expression profiles, using cluster analysis of all qRT-PCR data (Figure 3d and Supplementary Figure S4). Hierarchical clustering organized gene expression in five main clusters. Clusters $(A)(B)$ and $(C)$ grouped genes with high transcription levels in the $\mathrm{NAc}, \mathrm{CeA}$, or $\mathrm{CPu}$ of mutant mice, respectively. Sixteen genes in clusters $(A)$ and $(C)$ code GABAergic receptors/receptor subunits and transporters (Supplementary Figure S4d), consistent with increased number of striatal symmetrical synapses in knockout animals. Cluster $(D)$ retained our attention for 
gathering genes (zoomed in Figure 3d) with consistent lowered mRNA levels in the $\mathrm{CPu}$ and NAc of Oprm1 ${ }^{-1-}$ mice, as compared with controls. Remarkably, 14 genes in cluster $(D)$ code glutamate receptors/receptor subunits and interacting proteins present in PSDs, further supporting electron microscopic data showing reduced PSD surface in mutants. Three major actors of the glutamate pathway, Gria2, Homer3, and Camk2a, showed low transcript levels across all the tested brain regions, suggesting widespread alterations of glutamate signaling. Among genes coding metabotropic glutamate receptors, only Grm4 displayed statistically significant downregulated expression and clustered in $(D)$. Together, results suggest that mu opioid receptor gene knockout alters both GABA and glutamate signaling in the basal ganglia.

\section{The Positive mGluR4 Allosteric Modulator VU0155041 Alleviates Autistic Symptoms in Oprm1 ${ }^{-1-}$ Mice: Comparison with the Atypical Antipsychotic Risperidone}

Our qRT-PCR analysis revealed decreased transcription of Grm4, coding metabotropic glutamate receptors mGluR4, in the $\mathrm{CPu}$ and $\mathrm{NAc}$ of Oprm1 $1^{-1-}$ animals (framed in Figure 3d). We reasoned that restoring mGluR4 activity in mutant mice using a positive allosteric modulator (PAM) may relieve behavioral deficits in these animals. We compared efficiency of a chronic treatment (7-17 days; Supplementary Figure S5a) with VU0155041, a mGluR4 PAM $(5 \mathrm{mg} / \mathrm{kg})$, or risperidone $(0.2 \mathrm{mg} / \mathrm{kg})$ in improving autistic symptoms. Chronic treatment was chosen for better translational value and to match published conditions of risperidone administration in mice (Penagarikano et al, 2011). We used risperidone as a reference, as atypical antipsychotics remain the only approved drugs for symptomatic treatment of ASDs. Risperidone acts at D2 and 5HT2a receptors and alleviates aggression and repetitive/selfinjurious behavior but fails to significantly improve social abilities (Maher and Theodore, 2012).

Risperidone and VU0155041 treatments demonstrated beneficial effects in the social interaction test by increasing the time spent in close contact and frequency of nose and paw contacts in mutants. Risperidone, however, failed to increase the duration of close contacts, while VU0155041 normalized or even increased this duration. Both treatments reduced grooming, especially after social contact (statistics in Supplementary Tables S6 and S7), when treated animals interacted with a naive WT conspecific (Figure 4a and b). Risperidone reduced activity of $\mathrm{Oprm} 1^{+/+}$control mice in our strain, as shown by decreased paw contacts and following in this test, confirmed by reduced horizontal activity and coherent with decreased striatal DA levels (Supplementary Figure S5b and c; Supplementary Table S8), in agreement with well-described adverse sedative effects of atypical antipsychotics (Maher and Theodore, 2012). In contrast, VU0155041 increased paw contacts and horizontal activity in both $\mathrm{Oprm} 1^{+/+}$and $\mathrm{Oprm} 1^{-1-}$ lines (Supplementary Figure S5d). To assess whether risperidone and VU0155041 treatments similarly restore initiation of social interaction despite opposing effects on activity, we performed the social interaction test with each experimental animal encountering a gender-, genotype-, and treatment- matched conspecific (Supplementary Figure S5g). No interactions could be observed between stimulus and test mice under risperidone for both Oprm1 $1^{+1+}$ and Oprm1 $1^{-1-}$ lines, whereas VU0155041 fully restored social behavior in mutant mice, with no effect in Oprm1 ${ }^{+/+}$animals (Supplementary Figure S5h; statistics in Supplementary Table S9). Finally, we assessed the effects of mGluR4 PAM treatment on neuronal activity induced by social exposure by measuring the transcript levels of two immediate early genes, $C$-fos and Egr1, following direct social interaction (second paradigm, Supplementary Figure S5g). We used qRT-PCR for high detection sensitivity and focused on brain regions involved in the control of reward processes and/or social behavior (PFC, NAc, VTA, and MeA; van Kerkhof et al, 2013; Weathington et al, 2012). We confirmed that under these conditions chronic VU0155041 administration alleviates deficient social behavior in mutant mice (Figure 4c and Supplementary Table S10). Concomitantly, this treatment normalized the decreased expression of $C$-fos in the NAc, VTA, and MeA of mutant animal after social interaction. Similarly, VU0155041 normalized or tended to normalize decreased expression of Egr1 in the VTA and MeA, respectively, and brought increased Egrl transcription in the NAc back to WT levels in Oprm1 ${ }^{-1-}$ mice (Figure 4d). These effects were not observed at the level of PFC. Thus mGluR4 PAM treatment, when administered to mutant mice, restored neuronal reactivity induced by social exposure in specific brain regions associated with reward and social behavior.

Neither risperidone nor VU0155041 improved nesting scores in mutant animals (Supplementary Figure S5e). In contrast, both suppressed stereotyped grooming and circling (Figure 5a and Supplementary Figure S5f) and normalized marble burying in Oprm1 ${ }^{-{ }_{-}^{-}}$mice. VU0155041, however, increased stereotypic marble burying in Oprm $1^{+/+}$mice (Figure 5b). Risperidone had no detectable effect in the NSF; in contrast, VU0155041 restored a short latency to eat in mutant animals (Figure 5c; statistics in Supplementary Tables S6 and S7). Compared with risperidone, the mGluR4 PAM was thus more efficient in alleviating social deficits and anxiety in $\mathrm{Oprm} 1^{-1-}$ mice, with no depressive effect on general activity. To our knowledge, this is the first evidence that mGluR4 represents a promising pharmacological target in the context of ASDs.

\section{DISCUSSION}

Altogether, our data demonstrate that Oprm1 deletion is sufficient to produce a comprehensive spectrum of behavioral, neuroanatomical, biochemical, and genetic landmarks of ASDs. Behaviorally, marked social interaction deficits in mutant animals extend previous findings of reduced maternal attachment and altered social and communication skills in these mice (Cinque et al, 2012; Moles et al, 2004; Wohr et al, 2011) to definitely demonstrate that mu opioid receptors are essential for establishing appropriate social behavior. Stereotyped and perseverative behaviors detected in Oprm $1^{-1-}$ mice further complete autistic-like core symptoms in these animals. In addition, mutant mice show multiple comorbid symptoms of ASD, including aggressiveness, exacerbated anxiety, motor 
a

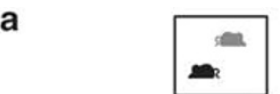

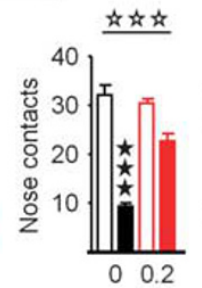
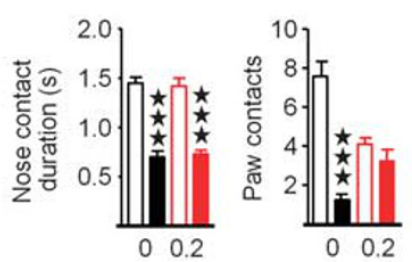

Saline

Risperidone VU0155041
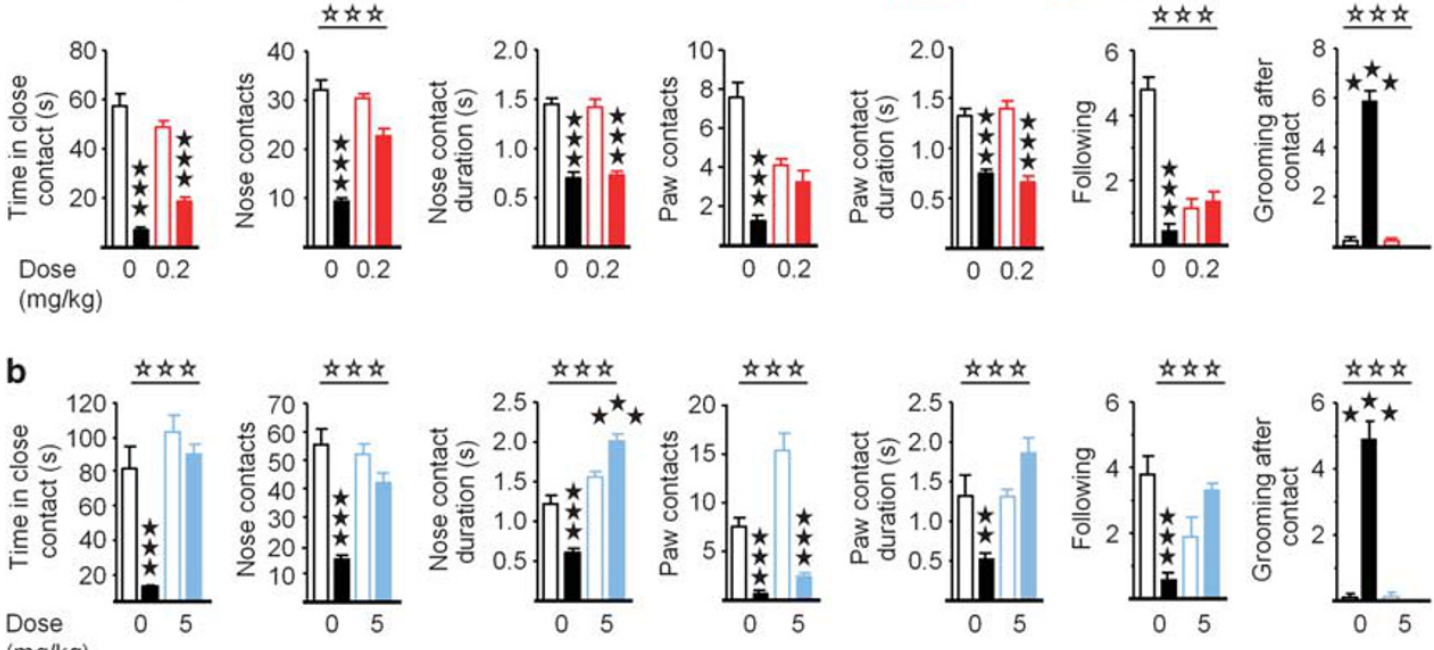

c
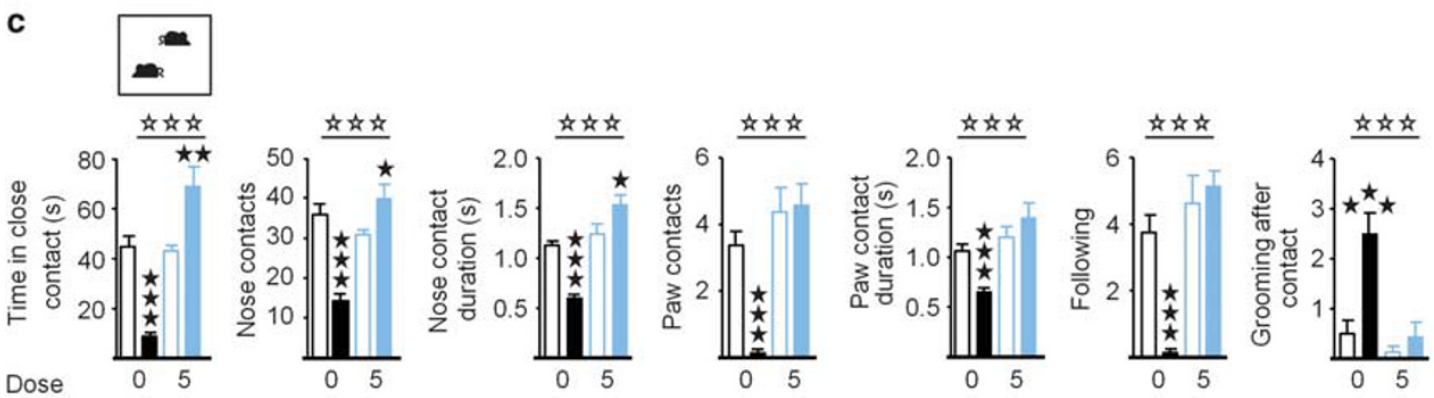

$(\mathrm{mg} / \mathrm{kg}$ )
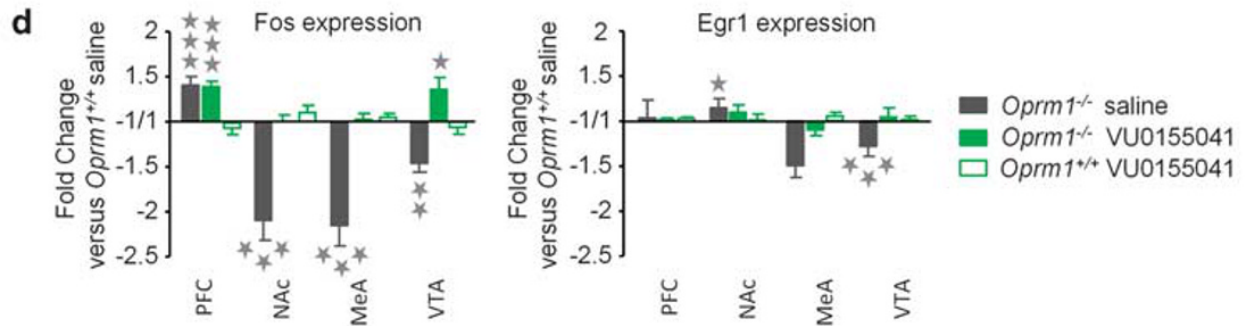

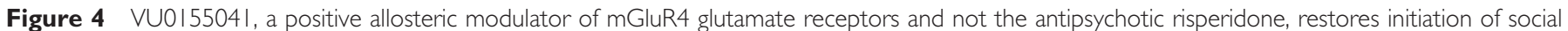
interaction in Oprm $I^{-1-}$ mice. (a) When a naive wild-type social partner is used in the dyadic interaction test, chronic risperidone $(0.2 \mathrm{mg} / \mathrm{kg})$ restores normal frequency of nose and paw contacts as well as grooming episodes but fails to increase the time spent in close contact, the duration of nose and paw contacts, and the number of following episodes in mutant animals ( $n=14$ per genotype and treatment). (b) Chronic treatment with VU0 I5504I (5 mg/kg) improves all these parameters except the number of following episodes and increases the occurrence of paw contacts in controls (9-10 per genotype and treatment). (c) Using a paradigm in which each experimental mouse encounters a genotype and treatment-matched animal confirms the efficiency of VU0I5504I to normalize or even facilitate social interaction in mutant mice, including the frequency of following episodes ( $n=7-8$ per genotype and treatment). (d) Chronic VUOI5504I administration normalizes deficient C-fos expression following social interaction in the NAc, MeA, and VTA as well as deficient Egrl expression in the VTA of Oprm ${ }^{-1}$ - mice. Data are presented as mean \pm SEM. Open stars: treatment effect; black stars: genotype $\times$ treatment interaction (post-hoc: Newman-Keuls test); grey stars: comparison with saline-treated Oprm ${ }^{+1+}$ mice. One star $p<0.05$, two stars $p<0.01$, three stars $p<0.001$.

clumsiness, and increased susceptibility to seizures. Together with previously described impairments in spatial learning (Jamot et al, 2003), lowered nociceptive thresholds (Gaveriaux-Ruff and Kieffer, 2002), and reduced gastrointestinal motility (Roy et al, 1998), mice lacking mu opioid receptors recapitulate the broadest autistic syndrome, including comorbid signs (Argyropoulos et al, 2013; Veenstra-VanderWeele and Blakely, 2012) but not gender bias (usually not tested in mouse models), ever described in preclinical research. Oprm1 ${ }^{-1-}$ mice thus display remarkable face validity as an animal model of this pathology.

Social interactions have been demonstrated to be intrinsically rewarding (Neuhaus et al, 2010; Trezza et al, 2010). Interestingly, imaging and psychophysical studies have provided evidence for reward dysfunction in autistic patients (Dichter et al, 2012; Kohls et al, 2012). These data 
a

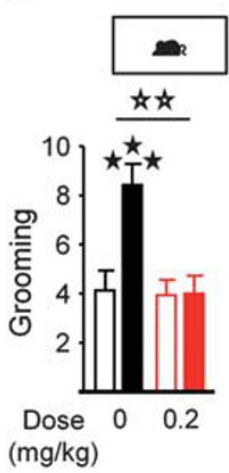

b

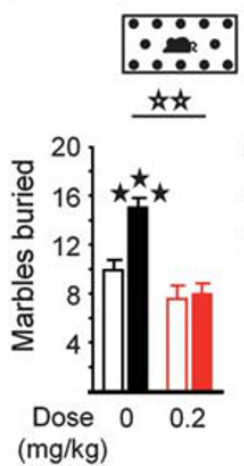

Saline Risperidone VU0155041
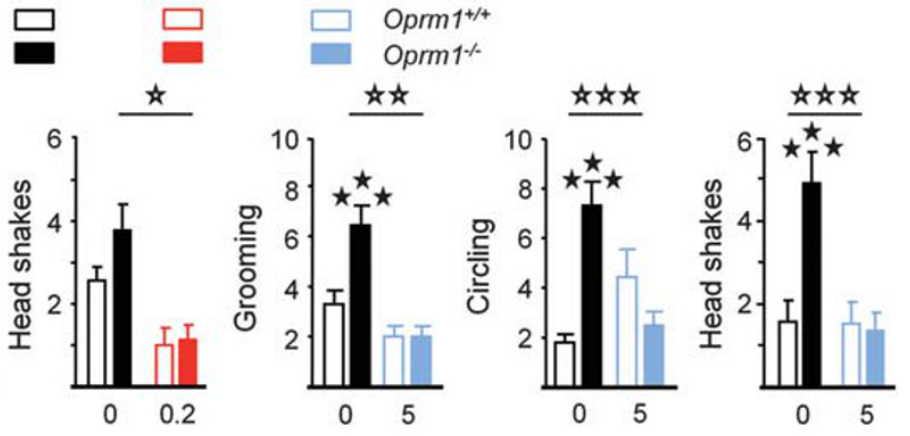

C

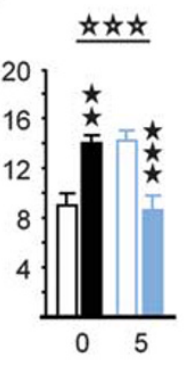

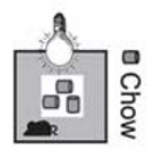
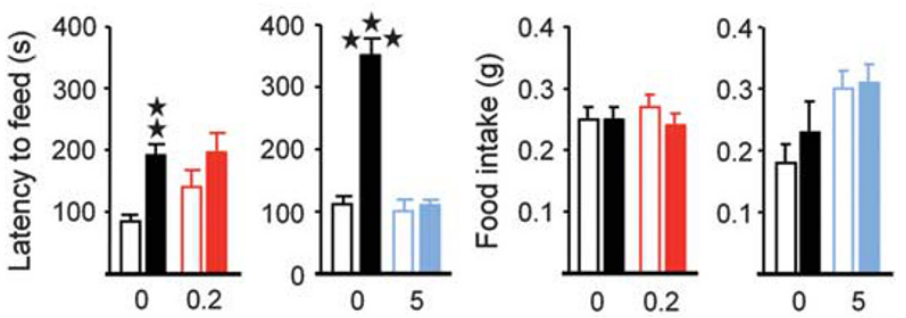

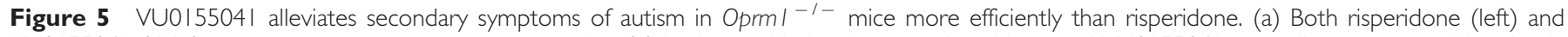
VUOI5504I (right) treatments suppress motor stereotypies. (b) In the marble burying test, risperidone and VU0 I5504I normalize stereotyped burying in

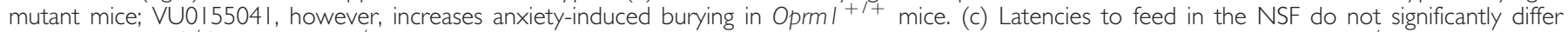

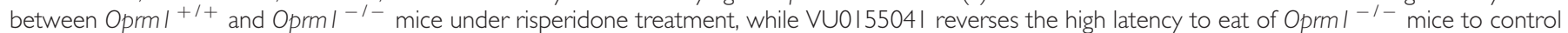

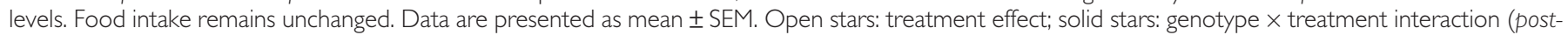
hoc: Newman-Keuls); One star $p<0.05$, two stars $p<0.01$, three stars $p<0.001$. See also Supplementary Figure S5.

are coherent with a recently emerged reward/motivation deficiency theory of autism (Chevallier et al, 2012; Dichter and Adolphs, 2012), which proposes that disrupted social interest in ASD patients results from early deficits in their motivation for attending social stimuli, as well as enjoying and prolonging reciprocal social interactions. In humans, neural sensitivity to social rejection (Way et al, 2009) and social hedonic capacity (Troisi et al, 2011) show significant association with a common variant (A118G) of Oprm1, and social acceptance activates mu opioid receptors in the NAc (Hsu et al, 2013), suggesting that mu opioid receptors are involved in social reward. $\mathrm{Mu}$ opioid receptors indeed have a critical role in mediating reward processes (Le Merrer et al, 2009). Interestingly, Oprm $1^{-/}$mice show altered social place preference (Cinque et al, 2012) and blunted induction of $C$-fos and Egr1 expression following social challenge in brain regions controlling reward processes and social recognition (NAc, VTA, MeA). These data suggest that social reward is compromised in these animals and thus substantiate the reward deficiency theory. Reduced mu opioid receptor function in early life, therefore, could represent a major molecular mechanism underlying reward and social behavior deficits in ASDs. Altered mu opioid receptor signaling would result either from invalidating mutations of Oprm1, as identified in several patients with ASD (SFARIgene ${ }^{2.0}$ database https://gene.sfari.org/autdb/ Welcome.do), or from genetic or environmental factors that hamper mu opioid receptor activity. Alterations in other neurotransmitter systems may also contribute, and the profound decrease in Oxt gene expression in the NAc of Oprm $1^{-/-}$mice is most striking. Remarkably, oxytocin release in this region has been demonstrated to have a key role in social reward (Dolen et al, 2013). Moreover, this neuropeptide has been involved in the etiology of autism (Insel, 2010), and oxytocin treatment demonstrated beneficial effects on social skills in ASD patients (Andari et al, 2010). Future studies will clarify mu opioid/oxytocin interactions and determine whether low oxytocin activity may result from deficient mu opioid receptor signaling.

At the cellular and molecular level, mutant mice also show most features characterizing ASDs in animal and clinical research. Oprm $1^{-/-}$mice exposed to a conflict situation showed increased and decreased neuronal activation in anxiety- and reward-associated brain structures, respectively, mimicking activation patterns observed in autistic patients (Dichter et al, 2012; Kohls et al, 2012). High 5HT and NE concentrations in the dorsal raphe of mutant mice (Supplementary Table S8) parallel high blood levels for these two monoamines reported in autistic subjects (Lam et al, 2006). Altered expression of monoamine signaling genes (Slc6a2, Slc6a4, Htr2a, Maoa) is in line with the findings of ASD behavioral features elicited by increased monoaminergic activity (Bortolato and Shih, 2011). Mutant mice also showed altered expression for multiple genes 
associated with ASDs (Ecker et al, 2012a; Insel, 2010; State and Levitt, 2011). Finally, we collected anatomical and molecular evidence for altered glutamatergic neurotransmission, a feature common to several mouse models of ASD (Carlson, 2012; Peca et al, 2011; Won et al, 2012) and supported by genetic studies (Kelleher et al, 2012; Sato et al, 2012). Notably, expression of multiple genes coding major players of glutamate neurotransmission was downregulated in striatal regions.

We next tested therapeutic utility of Oprm $1^{-/-}$mice in the context of ASDs. Metabotropic glutamate receptors have received major attention as potential therapeutic targets for the treatment of ASDs (Carlson, 2012). Transcriptome analysis identified expression of Grm4, coding metabotropic glutamate receptors mGluR4, as significantly downregulated in the striatum of mutant animals. Grm4 shows a discrete pattern of mRNA expression in the brain, including striatal regions (Testa et al, 1994). High levels of presynaptic mGluR4 receptors are transported to nigral and pallidal output regions (Bradley et al, 1999; Corti et al, 2002) where they modulate GABA release. Activation of these receptors notably reduces GABAergic striatopallidal neurotransmission, with beneficial effects on dyskinesia/akinesia in animal models of Parkinson's disease (Amalric et al, 2013). Moreover, PAMs of mGluR4 receptors decrease anxietylike behavior in the marble burying and Volgel's conflict tests (Duvoisin et al, 2011; Slawinska et al, 2013). We thus reasoned that restoring mGluR4 activity in mutant mice using such compound may ameliorate behavioral deficits in these animals. We found that chronic treatment with the PAM VU0155041 was more efficient than the antipsychotic risperidone in improving autistic-like symptoms in Oprm $1^{-/}$mice, especially regarding social behavior, without sedative side effects. Interestingly, a chronic moderate dose of risperidone reduced striatal dopamine levels in our mice. Therefore, common beneficial effects of risperidone and VU0155041 on autistic-like deficits in our mouse model, despite their distinct molecular targets, may lie in their shared ability to moderate striatopallidal output, an intriguing novel hypothesis in the field. Remarkably, VU0155041 treatment in Oprm1 $1^{-/-}$mice normalized immediate early gene expression induced by social exposure in several brain regions processing reward and social recognition, suggesting that facilitation of mGluR4 signaling was able to restore social reward in these animals.

In conclusion, this study substantiates the notion that ASDs could be considered an extreme case of early-onset deficient reward processes and proposes facilitation of mGluR4 receptor activity as a promising novel therapeutic strategy. Future investigations will aim at better delineating the impact of mu opioid receptor deletion across brain regions and along the lifespan as a trigger for autistic syndrome, using local or time-controlled manipulations of gene expression.

\section{FUNDING AND DISCLOSURE}

This work was supported by the Centre National de la Recherche Scientifique (CNRS), Institut National de la Santé et de la Recherche Médicale (INSERM), and Université de Strasbourg. JLM acknowledges postdoctoral fellowship from the Fondation Université de Strasbourg, generously funded by Pierre Fabre Laboratories. We thank the National Institutes of Health (NIAAA no. 16658 and NIDA no. 005010) for financial support. The authors declare no conflict of interest.

\section{ACKNOWLEDGEMENTS}

We thank C Gaveriaux-Ruff and A-M Ouagazzal for critical reading of the manuscript; $M$ Perdomini for technical advice in performing the footprint assay; A Wrzesinski for fruitful discussions; A Stephan, P Sin Chung, and A Parlog for their assistance; and A Matifas, $G$ Duval, and D Memedov for animal care.

\section{AUTHOR CONTRIBUTIONS}

JLM, JAJB, and BLK designed the experiments. JLM and JAJB performed and analyzed behavioral, immunohistochemical, qRT-PCR, and pharmacological experiments. DC performed and analyzed HPLC dosage of monoamine levels in brain tissue. CS and YS performed and analyzed electron microscopic experiments. JLM, JAJB, YS, and BLK interpreted the results. JLM, JAJB, and BLK wrote the article. JLM and BLK contributed equally to this work. All the authors discussed the results and commented on the manuscript.

\section{REFERENCES}

Albelda N, Joel D (2012). Animal models of obsessive-compulsive disorder: exploring pharmacology and neural substrates. Neurosci Biobehav Rev 36: 47-63.

Amalric M, Lopez S, Goudet C, Fisone G, Battaglia G, Nicoletti F et al (2013). Group III and subtype 4 metabotropic glutamate receptor agonists: discovery and pathophysiological applications in Parkinson's disease. Neuropharmacology 66: 53-64.

Andari E, Duhamel JR, Zalla T, Herbrecht E, Leboyer M, Sirigu A (2010). Promoting social behavior with oxytocin in highfunctioning autism spectrum disorders. Proc Natl Acad Sci USA 107: 4389-4394.

Argyropoulos A, Gilby KL, Hill-Yardin EL (2013). Studying autism in rodent models: reconciling endophenotypes with comorbidities. Front Hum Neurosci 7: 417.

Aupperle RL, Paulus MP (2010). Neural systems underlying approach and avoidance in anxiety disorders. Dialogues Clin Neurosci 12: 517-531.

Bortolato M, Shih JC (2011). Behavioral outcomes of monoamine oxidase deficiency: preclinical and clinical evidence. Int Rev Neurobiol 100: 13-42.

Bradley SR, Standaert DG, Rhodes KJ, Rees HD, Testa CM, Levey AI et al (1999). Immunohistochemical localization of subtype 4a metabotropic glutamate receptors in the rat and mouse basal ganglia. J Comp Neurol 407: 33-46.

Burkett JP, Spiegel LL, Inoue K, Murphy AZ, Young LJ (2011). Activation of mu-opioid receptors in the dorsal striatum is necessary for adult social attachment in monogamous prairie voles. Neuropsychopharmacology 36: 2200-2210.

Buxbaum JD, Betancur C, Bozdagi O, Dorr NP, Elder GA, Hof PR (2012). Optimizing the phenotyping of rodent ASD models: enrichment analysis of mouse and human neurobiological phenotypes associated with high-risk autism genes identifies morphological, electrophysiological, neurological, and behavioral features. Mol Autism 3: 1. 
Carlson GC (2012). Glutamate receptor dysfunction and drug targets across models of autism spectrum disorders. Pharmacol Biochem Behav 100: 850-854.

Chevallier C, Kohls G, Troiani V, Brodkin ES, Schultz RT (2012). The social motivation theory of autism. Trends Cogn Sci 16: 231-239.

Cinque C, Pondiki S, Oddi D, Di Certo MG, Marinelli S, Troisi A et al (2012). Modeling socially anhedonic syndromes: genetic and pharmacological manipulation of opioid neurotransmission in mice. Transl Psychiatry 2: e155.

Corti C, Aldegheri L, Somogyi P, Ferraguti F (2002). Distribution and synaptic localisation of the metabotropic glutamate receptor 4 (mGluR4) in the rodent CNS. Neuroscience 110: 403-420.

Crawley JN (2007). Mouse behavioral assays relevant to the symptoms of autism. Brain Pathol 17: 448-459.

Defensor EB, Corley MJ, Blanchard RJ, Blanchard DC (2012). Facial expressions of mice in aggressive and fearful contexts. Physiol Behav 107: 680-685.

Delorme R, Ey E, Toro R, Leboyer M, Gillberg C, Bourgeron T (2013). Progress toward treatments for synaptic defects in autism. Nat Med 19: 685-694.

Di Martino A, Kelly C, Grzadzinski R, Zuo XN, Mennes M, Mairena MA et al (2011). Aberrant striatal functional connectivity in children with autism. Biol Psychiatry 69: 847-856.

Dichter G, Adolphs R (2012). Reward processing in autism: a thematic series. J Neurodev Disord 4: 20.

Dichter GS, Richey JA, Rittenberg AM, Sabatino A, Bodfish JW (2012). Reward circuitry function in autism during face anticipation and outcomes. J Autism Dev Disord 42: 147-160.

Dolen G, Darvishzadeh A, Huang KW, Malenka RC (2013). Social reward requires coordinated activity of nucleus accumbens oxytocin and serotonin. Nature 501: 179-184.

Duvoisin RM, Villasana L, Davis MJ, Winder DG, Raber J (2011). Opposing roles of mGluR8 in measures of anxiety involving nonsocial and social challenges. Behav Brain Res 221: 50-54.

Ecker C, Spooren W, Murphy DG (2012a). Translational approaches to the biology of autism: false dawn or a new era? Mol Psychiatry 18: 435-442.

Ecker C, Suckling J, Deoni SC, Lombardo MV, Bullmore ET, Baron-Cohen S et al (2012b). Brain anatomy and its relationship to behavior in adults with autism spectrum disorder: a multicenter magnetic resonance imaging study. Arch Gen Psychiatry 69: 195-209.

Filliol D, Ghozland S, Chluba J, Martin M, Matthes HW, Simonin F et al (2000). Mice deficient for delta- and mu-opioid receptors exhibit opposing alterations of emotional responses. Nat Genet 25: $195-200$.

Gaveriaux-Ruff C, Kieffer BL (2002). Opioid receptor genes inactivated in mice: the highlights. Neuropeptides 36: 62-71.

Grecksch G, Becker A, Schroeder H, Kraus J, Loh H, Hollt V (2004). Accelerated kindling development in mu-opioid receptor deficient mice. Naunyn Schmiedebergs Arch Pharmacol 369: 287-293.

Green D, Charman T, Pickles A, Chandler S, Loucas T, Simonoff E et al (2009). Impairment in movement skills of children with autistic spectrum disorders. Dev Med Child Neurol 51: 311-316.

Horder J, Lavender T, Mendez MA, O’Gorman R, Daly E, Craig MC et al (2013). Reduced subcortical glutamate/glutamine in adults with autism spectrum disorders: a [(1)H]MRS study. Transl Psychiatry 3: e279.

Hsu DT, Sanford BJ, Meyers KK, Love TM, Hazlett KE, Wang H et al (2013). Response of the mu-opioid system to social rejection and acceptance. Mol Psychiatry 18: 1211-1217.

Ide S, Sora I, Ikeda K, Minami M, Uhl GR, Ishihara K (2010). Reduced emotional and corticosterone responses to stress in mu-opioid receptor knockout mice. Neuropharmacology 58: 241-247.
Insel TR (2010). The challenge of translation in social neuroscience: a review of oxytocin, vasopressin, and affiliative behavior. Neuron 65: 768-779.

Jamot L, Matthes HW, Simonin F, Kieffer BL, Roder JC (2003). Differential involvement of the mu and kappa opioid receptors in spatial learning. Genes Brain Behav 2: 80-92.

Jang CG, Lee SY, Loh HH, Ho IK (2001). Lack of mu-opioid receptor leads to an increase in the NMDA receptor subunit mRNA expression and NMDA-induced convulsion. Brain Res Mol Brain Res 94: 105-111.

Johnson CP, Myers SM (2007). Identification and evaluation of children with autism spectrum disorders. Pediatrics 120: $1183-1215$

Just MA, Keller TA, Malave VL, Kana RK, Varma S (2012). Autism as a neural systems disorder: a theory of frontal-posterior underconnectivity. Neurosci Biobehav Rev 36: 1292-1313.

Kelleher RJ 3rd, Geigenmuller U, Hovhannisyan H, Trautman E, Pinard R, Rathmell B et al (2012). High-throughput sequencing of mGluR signaling pathway genes reveals enrichment of rare variants in autism. PLoS One 7: e35003.

Kohls G, Schulte-Ruther M, Nehrkorn B, Muller K, Fink GR, Kamp-Becker I et al (2012). Reward system dysfunction in autism spectrum disorders. Soc Cogn Affect Neurosci 8: $565-572$.

Lam KS, Aman MG, Arnold LE (2006). Neurochemical correlates of autistic disorder: a review of the literature. Res Dev Disabil 27: 254-289.

Le Merrer J, Becker JA, Befort K, Kieffer BL (2009). Reward processing by the opioid system in the brain. Physiol Rev 89: 1379-1412.

Le Merrer J, Befort K, Gardon O, Filliol D, Darcq E, Dembele D et al (2012). Protracted abstinence from distinct drugs of abuse shows regulation of a common gene network. Addict Biol 17: $1-12$.

Le Merrer J, Rezai X, Scherrer G, Becker JA, Kieffer BL (2013). Impaired hippocampus-dependent and facilitated striatumdependent behaviors in mice lacking the delta opioid receptor. Neuropsychopharmacology 38: 1050-1059.

Maher AR, Theodore G (2012). Summary of the comparative effectiveness review on off-label use of atypical antipsychotics. J Managed Care Pharm 18: S1-20.

Matthes HW, Maldonado R, Simonin F, Valverde O, Slowe S, Kitchen I et al (1996). Loss of morphine-induced analgesia, reward effect and withdrawal symptoms in mice lacking the mu-opioid-receptor gene. Nature 383: 819-823.

Mazurek MO, Vasa RA, Kalb LG, Kanne SM, Rosenberg D, Keefer A et al (2013). Anxiety, sensory over-responsivity, and gastrointestinal problems in children with autism spectrum disorders. J Abnorm Child Psychol 41: 165-176.

Moles A, Kieffer BL, D'Amato FR (2004). Deficit in attachment behavior in mice lacking the mu-opioid receptor gene. Science 304: 1983-1986.

Neuhaus E, Beauchaine TP, Bernier R (2010). Neurobiological correlates of social functioning in autism. Clin Psychol Rev 30: 733-748.

Oddi D, Crusio WE, D'Amato FR, Pietropaolo S (2013). Monogenic mouse models of social dysfunction: implications for autism. Behav Brain Res 251: 75-84.

Peca J, Feliciano C, Ting JT, Wang W, Wells MF, Venkatraman TN et al (2011). Shank3 mutant mice display autistic-like behaviours and striatal dysfunction. Nature 472: 437-442.

Penagarikano O, Abrahams BS, Herman EI, Winden KD, Gdalyahu A, Dong H et al (2011). Absence of CNTNAP2 leads to epilepsy, neuronal migration abnormalities, and core autismrelated deficits. Cell 147: 235-246.

Rawleigh JM, Kemble ED (1992). Test-specific effects of FG-7142 on isolation-induced aggression in mice. Pharmacol Biochem Behav 42: 317-321. 
Robertson HR, Feng G (2011). Annual research review: transgenic mouse models of childhood-onset psychiatric disorders. J Child Psychol Psychiatry 52: 442-475.

Robinson SJ (2012). Childhood epilepsy and autism spectrum disorders: psychiatric problems, phenotypic expression, and anticonvulsants. Neuropsychol Rev 22: 271-279.

Rojas DC, Singel D, Steinmetz S, Hepburn S, Brown MS (2013). Decreased left perisylvian GABA concentration in children with autism and unaffected siblings. Neuroimage 86: 28-34.

Roy S, Liu HC, Loh HH (1998). mu-Opioid receptor-knockout mice: the role of mu-opioid receptor in gastrointestinal transit. Brain Res Mol Brain Res 56: 281-283.

Sato D, Lionel AC, Leblond CS, Prasad A, Pinto D, Walker S et al (2012). SHANK1 deletions in males with autism spectrum disorder. Am J Hum Genet 90: 879-887.

Slawinska A, Wieronska JM, Stachowicz K, Palucha-Poniewiera A, Uberti MA, Bacolod MA et al (2013). Anxiolytic- but not antidepressant-like activity of Lu AF21934, a novel, selective positive allosteric modulator of the $\mathrm{mGlu}(4)$ receptor. Neuropharmacology 66: 225-235.

State MW, Levitt P (2011). The conundrums of understanding genetic risks for autism spectrum disorders. Nat Neurosci 14: 1499-1506.

Testa CM, Standaert DG, Young AB, Penney JB Jr. (1994). Metabotropic glutamate receptor mRNA expression in the basal ganglia of the rat. J Neurosci 14: 3005-3018.

Trezza V, Baarendse PJ, Vanderschuren LJ (2010). The pleasures of play: pharmacological insights into social reward mechanisms. Trends Pharmacol Sci 31: 463-469.

Trezza V, Damsteegt R, Achterberg EJ, Vanderschuren LJ (2011). Nucleus accumbens mu-opioid receptors mediate social reward. J Neurosci 31: 6362-6370.
Troisi A, Frazzetto G, Carola V, Di Lorenzo G, Coviello M, D'Amato FR et al (2011). Social hedonic capacity is associated with the A118G polymorphism of the mu-opioid receptor gene (OPRM1) in adult healthy volunteers and psychiatric patients. Social Neurosci 6: 88-97.

van Kerkhof LW, Trezza V, Mulder T, Gao P, Voorn P, Vanderschuren LJ (2013). Cellular activation in limbic brain systems during social play behaviour in rats. Brain Struct Funct (e-pub ahead of print).

Veenstra-VanderWeele J, Blakely RD (2012). Networking in autism: leveraging genetic, biomarker and model system findings in the search for new treatments. Neuropsychopharmacology 37: 196-212.

Way BM, Taylor SE, Eisenberger NI (2009). Variation in the mu-opioid receptor gene (OPRM1) is associated with dispositional and neural sensitivity to social rejection. Proc Natl Acad Sci USA 106: 15079-15084.

Weathington JM, Strahan JA, Cooke BM (2012). Social experience induces sex-specific fos expression in the amygdala of the juvenile rat. Horm Behav 62: 154-161.

White SW, Kreiser NL, Pugliese C, Scarpa A (2012). Social anxiety mediates the effect of autism spectrum disorder characteristics on hostility in young adults. Autism 16: 453-464.

Whyatt C, Craig C (2013). Sensory-motor problems in Autism. Front Integr Neurosci 7: 51.

Wohr M, Moles A, Schwarting RK, D'Amato FR (2011). Lack of social exploratory activation in male mu-opioid receptor $\mathrm{KO}$ mice in response to playback of female ultrasonic vocalizations. Soc Neurosci 6: 76-87.

Won H, Lee HR, Gee HY, Mah W, Kim JI, Lee J et al (2012). Autistic-like social behaviour in Shank2-mutant mice improved by restoring NMDA receptor function. Nature 486: 261-265.

Supplementary Information accompanies the paper on the Neuropsychopharmacology website (http://www.nature.com/npp) 